\title{
Impact of repeated procedural pain-related stress in infants born very preterm
}

\author{
Jillian Vinall ${ }^{1,2}$ and Ruth E. Grunau ${ }^{1-4}$
}

The majority of infants born very preterm (24-32 wk gestational age) now survive; however, long-term neurodevelopmental and behavioral problems remain a concern. As part of their neonatal care, very preterm infants undergo repeated painful procedures during a period of rapid brain development and programming of stress systems. Infants born this early have the nociceptive circuitry required to perceive pain, however, their sensory systems are functionally immature. An imbalance of excitatory vs. inhibitory processes leads to increased nociceptive signaling in the central nervous system. Specific cell populations in the central nervous system of preterm neonates are particularly vulnerable to excitoxicity, oxidative stress, and inflammation. Neonatal rat models have demonstrated that persistent or repeated pain increases apoptosis of neurons, and neonatal pain and stress lead to anxiety-like behaviors during adulthood. In humans, greater exposure to neonatal pain-related stress has been associated with altered brain microstructure and stress hormone levels, as well as with poorer cognitive, motor, and behavioral neurodevelopment in infants and children born very preterm. Therefore, it is important that pain-related stress in preterm neonates is accurately identified, appropriately managed, and that pain management strategies are evaluated for protective or adverse effects in the long term.

\section{PAIN PROCESSING IN INFANTS BORN VERY PRETERM}

Infants born preterm, especially those born between 24 and $32 \mathrm{wk}$ gestational age (very preterm) are exposed to repeated procedural pain-related stress, during a period of physiological vulnerability and rapid brain development, as part of their lifesaving care in the neonatal intensive care unit (NICU). Preterm infants have the nociceptive circuitry required to perceive pain, however, this system is functionally immature $(1,2)$. Cutaneous receptive fields are large in the neonate, and peripheral sensory fibers are sensitive to tissue injury and have reduced peak firing frequencies (2-5). Axon terminals temporarily overlap in lamina II of the spinal cord with low-threshold tactile inputs, making it more difficult for neonates to discriminate between noxious and non-noxious stimuli $(6,7)$. Thus, prior to $35 \mathrm{wk}$ gestation, infants demonstrate central sensitization to repeated procedures $(3,8-12)$. This transition has been confirmed by electrophysiological (electroencephalogram) recordings, since responses to heel lance were dispersed neuronal bursts in very preterm neonates, in contrast to the modality-specific, localized, evoked potentials seen at $\sim 36 \mathrm{wk}$ postmenstrual age (13). Moreover, changes in the electroencephalogram recordings of preterm infants correspond to the disappearance of the radial glia and increase in complexity of the cerebral cortex $(14,15)$. However, descending modulation of nociceptive activity in the dorsal horn of the spinal cord develops later, beyond term equivalent age $(16,17)$. Therefore, given that infants born very preterm have reduced localization and specification to noxious stimuli, become sensitized to repeated noxious stimuli and lack descending inhibitory control, identifying, relieving, and preventing pain are very important aspects of NICU care.

\section{RESPONSES TO PAINFUL PROCEDURES IN INFANTS BORN VERY PRETERM}

Neonatal pain assessment instruments code a variety of behavioral and physiological responses (e.g., facial actions, body movements, cry, heart rate, respiratory rate, blood pressure, and oxygen saturation) in order to quantify pain in nonverbal patients $(18,19)$. However, these indicators are not specific to pain, and may also represent agitation or distress. Responses to neonatal pain also vary based on GA, sleepwake state, illness severity, as well as recency and duration of previous exposures to pain and noninvasive interventions $(9-11,20,21)$. Therefore, clinicians are faced with the difficult task of discriminating and appropriately managing pain in infants born preterm. Dampened behavioral and physiological responses to pain do not necessarily represent absence of nociceptive processing in the central nervous system $(22,23)$. Pharmacological care is not ideal for routine pain management (24), and while nonpharmacologic management is recommended as a first step, often invasive procedures in the NICU are still performed without support (25). Unmanaged pain may have substantive effects on the developing brain and stress systems of premature neonates, however, pain management remains a challenge. 


\section{Neonatal pain in infants born preterm $\quad$ Review}

REPEATED NEONATAL PAIN-RELATED STRESS IN INFANTS BORN VERY PRETERM

Stress hormones are glucocorticoids (cortisol in humans, corticosterone in rats) that regulate the transcription of genes throughout the body and the brain (26). Thus, prolonged activation of the HPA axis in physiologically immature neonates, can lead to long-term changes in hormonal (e.g., growth, glucocorticoid), physiological (e.g., metabolic, immune), and behavioral (anxiety, depression) systems (27-30). However, while very preterm infants are in the NICU, their cortisol levels are frequently lower than expected, considering the number procedures required during their hospitalization (31). This may represent an exhaustion of resources among these physiologically immature neonates, immaturity of the adrenal cortex, or other factors in this medical context. Greater exposure to painful procedures in the NICU has been associated with the reprogramming of the stress hormone system. Grunau et al. (32) found that greater cumulative neonatal procedural pain exposure was associated with lower cortisol responses to stress at $32 \mathrm{wk}$ postmenstrual age, independent of early illness severity and morphine exposure, and not accounted for by GA at birth. In contrast, in infants born at extremely low gestational age (ELGA: $24-28$ wk gestation) at 8 and 18 mo corrected age, cortisol levels were elevated, and the level was associated with exposure to higher numbers of skin-breaking procedures from birth to term equivalent age (33). Among infants born ELGA, there is evidence for a shift from low basal cortisol levels at 3 mo to relatively high levels at 8 and 18 mo corrected age, which suggests a biological "resetting" of endocrine stress systems (34). Rat pups exposed to long periods of maternal separation early in life, have fewer hippocampal glucocorticoid receptors, higher corticotropin releasing factor, adrenocorticotropin and corticosterone production, during adulthood (30). Long-term changes to stress responses appear to be due to the fact that regions rich in glucocorticoid receptors (e.g., hippocampus, prefrontal cortex), are particularly vulnerable to the effects of ongoing stress $(30,35)$.

\section{NEONATAL PAIN-RELATED STRESS AND THE DEVELOPING BRAIN}

Two cell populations are particularly vulnerable to injury in the premature brain: subplate neurons and preoligodendrocytes (36). Subplate neurons are among the first cells generated in the mammalian cerebral cortex, and are the first cortical neurons to receive excitatory synaptic inputs from thalamic axons, establishing a temporary link between thalamic axons and their final target in the cerebral cortex (37-39). Subplate neurons are particularly vulnerable to excitotoxic death, as was demonstrated by the selective ablation of subplate neurons after the administrations of glutamate agonist kainite into embryonic and postnatal kittens $(40,41)$, and in a model of hypoxia-ischemia in the neonatal rat (42). Glutamate n-methyl-D-aspartate receptors involved in the transmission of the pain signal are more active during early life because of the developmentally delayed expression of NR2A receptor subunits relative to NR2B. Therefore, repeated procedural pain may lead to excitotoxicity and apoptosis of the subplate neurons due to the excessive release of glutamate and influxes of calcium (43-46). Neonatal pain-related stress may also impact preoligodendrocytes, which ensheath axons prior to differentiating into myelin-producing oligodendrocytes (36). The immaturity of these cells makes them particularly vulnerable to reactive oxygen, nitrogen species, and cytokines secreted by microglia (47-51). Procedural pain induces both oxidative stress and inflammatory reactions $(52,53)$, and therefore may arrest the development of premyelinating cells.

Recently, studies have demonstrated for the first time that procedural pain/stress in very preterm infants is associated with abnormal brain development during neonatal intensive care, up to term-equivalent age $(54,55)$. These findings are supported by evidence from animal models that have demonstrated both inflammatory pain and repeated injections increase apoptosis in the neonatal rat brain $(56,57)$. Therefore, repeated exposure to procedural pain appears to impact neonatal brain development.

Importantly, associations between neonatal pain-related stress and brain development also appear to extend beyond the relationships observed in early life $(54,58)$. At $7 \mathrm{y}$ of age, higher numbers of skin-breaking procedures in the NICU were associated with thinner cortical gray matter in 21 out of 66 cerebral regions assessed, predominately affecting the frontal and parietal lobes (59). Moreover, among infants born ELGA, greater exposure to neonatal pain-related stress was also associated with alterations in spontaneous neuromagnetic activity (60). Therefore, it appears that repeated exposure to neonatal procedural pain/stress is associated with long-term alterations to neuronal structure and function.

\section{NEONATAL PAIN-RELATED STRESS AND NEURODEVELOPMENTAL OUTCOME}

Greater neonatal pain-related stress has been associated with lower cognitive and motor function at 8 and 18 mo corrected age, and higher internalizing (anxious/depressed) behaviors at 18 mo corrected age and at age 7 y (61-63). However, pain exposure may not in and of itself modify long-term outcomes of preterm children. Among children born ELGA, cumulative neonatal pain-related stress was associated with changes in spontaneous brain activity at school age, and these alterations in brain oscillations were negatively correlated with visual-perceptual abilities (60). Therefore, it appears that the influence of neonatal pain-related stress on long-term cognitive outcomes may be through altered brain function among children born ELGA.

\section{MANAGEMENT OF PAIN AND BRAIN PROTECTION IN THE NICU}

Pharmacological and environmental support strategies for pain management are frequently used in the NICU. Pharmacological management of pain, and possible long-term effects of analgesics, anesthetics, and sedatives, are complex topics that have been recently reviewed elsewhere (64-67). Due to concerns regarding short-term and possible long-term 
effects of pharmacological agents, current recommendations are that opiates and sedatives be used sparingly in the NICU for nonsurgical pain management of ventilated preterm neonates $(68,69)$. A number of environmental (nonpharmacologic) interventions are used for the management of routine acute procedural pain in the NICU (e.g., sucrose, swaddling, facilitated tucking, non-nutritive sucking, kangaroo care, breast feeding) (70,71). Currently, sucrose is the most widely used nonpharmacologic intervention for the treatment of minor procedures in preterm infants (72). However, while it is well established that oral sucrose reduces behavioral responses and sometimes physiological responses (71), sucrose does not appear to dampen electroencephalogram response to pain (22). It is important for future studies to examine the extent to which various pain management strategies may be brain protective.

Parent support to promote sensitive and responsive interactions during hospitalization of preterm infants in the NICU appears to improve white matter maturation (73). Moreover, in ELGA infants, positive maternal interaction at 18 mo CA was associated with lower cortisol levels (74). Positive parent interaction at 18 mo CA appeared to ameliorate negative effects of neonatal pain on stress-sensitive behaviors (62). Therefore, while more research is needed to optimize pain management strategies in the NICU, it is encouraging that initial studies suggest that sensitive and responsive caregiving appears to ameliorate some effects of neonatal pain-related stress on brain, stress, and behavioral outcomes.

\section{FUTURE PERSPECTIVES}

Exposure to repeated neonatal pain-related stress is associated with altered brain development, function, and neurodevelopmental outcome in children born preterm. Therefore, it is of the utmost importance that pain-related stress in preterm neonates is accurately identified and appropriately managed. Pain management is required for humane care of infants; however, there are major gaps in knowledge as to which management interventions may be brain protective, and to what degree.

\section{STATEMENT OF FINANCIAL SUPPORT}

R.E.G.'s research program is supported by the Eunice Kennedy Shriver National Institute of Child Health and Human Development grant R01 HD39783, and the Canadian Institutes of Health Research (CIHR) MOP86489, and she holds a Senior Scientist award from the Child and Family Research Institute. J.V. holds a CIHR Frederick Banting and Charles Best Doctoral Award, and is a member of the Pain in Child Health CIHR Strategic Training Initiative in Health Research.

Disclosure: The authors have no conflict of interest to disclose.

\section{REFERENCES}

1. Fitzgerald M. The development of nociceptive circuits. Nat Rev Neurosci 2005;6:507-20.

2. Fitzgerald M, Walker SM. Infant pain management: a developmental neurobiological approach. Nat Clin Pract Neurol 2009;5:35-50.

3. Andrews K, Fitzgerald M. The cutaneous withdrawal reflex in human neonates: sensitization, receptive fields, and the effects of contralateral stimulation. Pain 1994;56:95-101.

4. Jennings E, Fitzgerald M. Postnatal changes in responses of rat dorsal horn cells to afferent stimulation: a fibre-induced sensitization. J Physiol (Lond) 1998;509 (Pt 3):859-68.
5. Li J, Walker SM, Fitzgerald M, Baccei ML. Activity-dependent modulation of glutamatergic signaling in the developing rat dorsal horn by early tissue injury. J Neurophysiol 2009;102:2208-19.

6. Beggs S, Torsney C, Drew LJ, Fitzgerald M. The postnatal reorganization of primary afferent input and dorsal horn cell receptive fields in the rat spinal cord is an activity-dependent process. Eur J Neurosci 2002;16:1249-58.

7. Granmo M, Petersson P, Schouenborg J. Action-based body maps in the spinal cord emerge from a transitory floating organization. J Neurosci 2008;28:5494-503.

8. Fitzgerald M, Millard C, McIntosh N. Cutaneous hypersensitivity following peripheral tissue damage in newborn infants and its reversal with topical anaesthesia. Pain 1989;39:31-6.

9. Grunau RE, Oberlander TF, Whitfield MF, Fitzgerald C, Lee SK. Demographic and therapeutic determinants of pain reactivity in very low birth weight neonates at 32 weeks' postconceptional age. Pediatrics 2001;107:105-12.

10. Holsti L, Grunau RE, Oberlander TF, Whitfield MF. Prior pain induces heightened motor responses during clustered care in preterm infants in the NICU. Early Hum Dev 2005;81:293-302.

11. Holsti L, Grunau RE, Whifield MF, Oberlander TF, Lindh V. Behavioral responses to pain are heightened after clustered care in preterm infants born between 30 and 32 weeks gestational age. Clin J Pain 2006;22:757-64.

12. Walker SM, Tochiki KK, Fitzgerald M. Hindpaw incision in early life increases the hyperalgesic response to repeat surgical injury: critical period and dependence on initial afferent activity. Pain 2009;147:99-106.

13. Fabrizi L, Slater R, Worley A, et al. A shift in sensory processing that enables the developing human brain to discriminate touch from pain. Curr Biol 2011;21:1552-8.

14. McKinstry RC, Mathur A, Miller JH, et al. Radial organization of developing preterm human cerebral cortex revealed by non-invasive water diffusion anisotropy MRI. Cereb Cortex 2002;12:1237-43.

15. Vinall J, Grunau RE, Brant R, et al. Slower postnatal growth is associated with delayed cerebral cortical maturation in preterm newborns. Sci Transl Med 2013;5:168ra8.

16. van Praag H, Frenk H. The development of stimulation-produced analgesia (SPA) in the rat. Brain Res Dev Brain Res 1991;64:71-6.

17. Hathway GJ, Koch S, Low L, Fitzgerald M. The changing balance of brainstem-spinal cord modulation of pain processing over the first weeks of rat postnatal life. J Physiol (Lond) 2009;587(Pt 12):2927-35.

18. Holsti L, Grunau RE, Oberlander TF, Osiovich H. Is it painful or not? Discriminant validity of the Behavioral Indicators of Infant Pain (BIIP) scale. Clin J Pain 2008;24:83-8.

19. Stevens BJ, Johnston CC, Horton L. Multidimensional pain assessment in premature neonates: a pilot study. J Obstet Gynecol Neonatal Nurs 1993;22:531-41.

20. Ranger M, Johnston CC, Anand KJ. Current controversies regarding pain assessment in neonates. Semin Perinatol 2007;31:283-8.

21. van Dijk M, Tibboel D. Update on pain assessment in sick neonates and infants. Pediatr Clin North Am 2012;59:1167-81.

22. Slater R, Worley A, Fabrizi L, et al. Evoked potentials generated by noxious stimulation in the human infant brain. Eur J Pain 2010;14:321-6.

23. Slater R, Cornelissen L, Fabrizi L, et al. Oral sucrose as an analgesic drug for procedural pain in newborn infants: a randomised controlled trial. Lancet 2010;376:1225-32.

24. Carbajal R, Lenclen R, Jugie M, Paupe A, Barton BA, Anand KJ. Morphine does not provide adequate analgesia for acute procedural pain among preterm neonates. Pediatrics 2005;115:1494-500.

25. Johnston C, Barrington KJ, Taddio A, Carbajal R, Filion F. Pain in Canadian NICUs: have we improved over the past 12 years? Clin J Pain 2011;27:225-32.

26. Chrousos GP. Stress and disorders of the stress system. Nat Rev Endocrinol 2009;5:374-81.

27. Coplan JD, Andrews MW, Rosenblum LA, et al. Persistent elevations of cerebrospinal fluid concentrations of corticotropin-releasing factor in adult nonhuman primates exposed to early-life stressors: implications for the pathophysiology of mood and anxiety disorders. Proc Natl Acad Sci USA 1996;93:1619-23. 


\section{Neonatal pain in infants born preterm $\quad$ Review}

28. Lupien SJ, McEwen BS, Gunnar MR, Heim C. Effects of stress throughout the lifespan on the brain, behaviour and cognition. Nat Rev Neurosci 2009;10:434-45.

29. Heim C, Nemeroff CB. Neurobiology of early life stress: clinical studies. Semin Clin Neuropsychiatry 2002;7:147-59.

30. Meaney MJ, Diorio J, Francis D, et al. Early environmental regulation of forebrain glucocorticoid receptor gene expression: implications for adrenocortical responses to stress. Dev Neurosci 1996;18:49-72.

31. Peters KL. Neonatal stress reactivity and cortisol. J Perinat Neonatal Nurs 1998;11:45-59.

32. Grunau RE, Holsti L, Haley DW, et al. Neonatal procedural pain exposure predicts lower cortisol and behavioral reactivity in preterm infants in the NICU. Pain 2005;113:293-300.

33. Grunau RE, Weinberg J, Whitfield MF. Neonatal procedural pain and preterm infant cortisol response to novelty at 8 months. Pediatrics 2004;114:e77-84.

34. Grunau RE, Haley DW, Whitfield MF, Weinberg J, Yu W, Thiessen P. Altered basal cortisol levels at 3, 6, 8 and 18 months in infants born at extremely low gestational age. J Pediatr 2007;150:151-6.

35. McEwen BS. Protection and damage from acute and chronic stress: allostasis and allostatic overload and relevance to the pathophysiology of psychiatric disorders. Ann N Y Acad Sci 2004;1032:1-7.

36. Volpe JJ. Brain injury in premature infants: a complex amalgam of destructive and developmental disturbances. Lancet Neurol 2009;8:110-24.

37. Kostovic I, Judas M, Rados M, Hrabac P. Laminar organization of the human fetal cerebrum revealed by histochemical markers and magnetic resonance imaging. Cereb Cortex 2002;12:536-44.

38. Kostovic I, Judas M. Correlation between the sequential ingrowth of afferents and transient patterns of cortical lamination in preterm infants. Anat Rec 2002;267:1-6.

39. McQuillen PS, Ferriero DM. Perinatal subplate neuron injury: implications for cortical development and plasticity. Brain Pathol 2005;15:250-60.

40. Ghosh A, Antonini A, McConnell SK, Shatz CJ. Requirement for subplate neurons in the formation of thalamocortical connections. Nature 1990;347:179-81.

41. Ghosh A, Shatz CJ. Involvement of subplate neurons in the formation of ocular dominance columns. Science 1992;255:1441-3.

42. McQuillen PS, Sheldon RA, Shatz CJ, Ferriero DM. Selective vulnerability of subplate neurons after early neonatal hypoxia-ischemia. J Neurosci 2003;23:3308-15.

43. Qu Y, Vadivelu S, Choi L, et al. Neurons derived from embryonic stem (ES) cells resemble normal neurons in their vulnerability to excitotoxic death. Exp Neurol 2003;184:326-36.

44. McDonald JW, Johnston MV. Physiological and pathophysiological roles of excitatory amino acids during central nervous system development. Brain Res Brain Res Rev 1990;15:41-70.

45. Talos DM, Follett PL, Folkerth RD, et al. Developmental regulation of alpha-amino-3-hydroxy-5-methyl-4-isoxazole-propionic acid receptor subunit expression in forebrain and relationship to regional susceptibility to hypoxic/ischemic injury. II. Human cerebral white matter and cortex. J Comp Neurol 2006;497:61-77.

46. Deng W, Rosenberg PA, Volpe JJ, Jensen FE. Calcium-permeable AMPA/ kainate receptors mediate toxicity and preconditioning by oxygen-glucose deprivation in oligodendrocyte precursors. Proc Natl Acad Sci USA 2003;100:6801-6.

47. Back SA, Gan X, Li Y, Rosenberg PA, Volpe JJ. Maturation-dependent vulnerability of oligodendrocytes to oxidative stress-induced death caused by glutathione depletion. J Neurosci 1998;18:6241-53.

48. Back SA, Luo NL, Mallinson RA, et al. Selective vulnerability of preterm white matter to oxidative damage defined by F2-isoprostanes. Ann Neurol 2005;58:108-20.

49. Haynes RL, Folkerth RD, Keefe RJ, et al. Nitrosative and oxidative injury to premyelinating oligodendrocytes in periventricular leukomalacia. J Neuropathol Exp Neurol 2003;62:441-50.

50. Buntinx M, Moreels M, Vandenabeele F, et al. Cytokine-induced cell death in human oligodendroglial cell lines: I. Synergistic effects of IFN-gamma and TNF-alpha on apoptosis. J Neurosci Res 2004;76:834-45.
51. Pang Y, Cai Z, Rhodes PG. Effect of tumor necrosis factor-alpha on developing optic nerve oligodendrocytes in culture. J Neurosci Res 2005;80:22634.

52. Slater L, Asmerom Y, Boskovic DS, et al. Procedural pain and oxidative stress in premature neonates. J Pain 2012;13:590-7.

53. Hansson E. Could chronic pain and spread of pain sensation be induced and maintained by glial activation? Acta Physiol (Oxf) 2006;187:321-7.

54. Brummelte S, Grunau RE, Chau V, et al. Procedural pain and brain development in premature newborns. Ann Neurol 2012;71:385-96.

55. Smith GC, Gutovich J, Smyser C, et al. Neonatal intensive care unit stress is associated with brain development in preterm infants. Ann Neurol 2011;70:541-9.

56. Anand KJ, Garg S, Rovnaghi CR, Narsinghani U, Bhutta AT, Hall RW. Ketamine reduces the cell death following inflammatory pain in newborn rat brain. Pediatr Res 2007;62:283-90.

57. Dührsen L, Simons SH, Dzietko M, et al. Effects of repetitive exposure to pain and morphine treatment on the neonatal rat brain. Neonatology 2013;103:35-43.

58. Zwicker JG, Grunau RE, Adams E, et al. Score for neonatal acute physiology-II and neonatal pain predict corticospinal tract development in premature newborns. Pediatr Neurol 2013;48:123-129.e1.

59. Ranger M, Chau CM, Garg A, et al. Neonatal pain-related stress predicts cortical thickness at age 7 years in children born very preterm. PLoS ONE 2013;8:e76702.

60. Doesburg SM, Chau CM, Cheung TP, et al. Neonatal pain-related stress, functional cortical activity and visual-perceptual abilities in school-age children born at extremely low gestational age. Pain 2013;154:1946-52.

61. Grunau RE, Whitfield MF, Petrie-Thomas J, et al. Neonatal pain, parenting stress and interaction, in relation to cognitive and motor development at 8 and 18 months in preterm infants. Pain 2009;143:138-46.

62. Vinall J, Miller SP, Synnes AR, Grunau RE. Parent behaviors moderate the relationship between neonatal pain and internalizing behaviors at 18 months corrected age in children born very prematurely. Pain 2013;154:1831-9.

63. Ranger M, Synnes AR, Vinall J, Grunau RE. Internalizing behaviours in school-age children born very preterm are predicted by neonatal pain and morphine exposure. Eur J Pain 2013 (doi:10.1002/j.1532-2149.2013. 00431.x).

64. Anand KJ. Pharmacological approaches to the management of pain in the neonatal intensive care unit. J Perinatol 2007;27:Suppl 1:S4-S11.

65. Durrmeyer X, Vutskits L, Anand KJ, Rimensberger PC. Use of analgesic and sedative drugs in the NICU: integrating clinical trials and laboratory data. Pediatr Res 2010;67:117-27.

66. McPherson CC, Grunau RE. Neonatal pain control and neurologic effects of anesthetics and sedatives in preterm infants. Clin Perinatol 2014;41:209-27.

67. Marlow N. Anesthesia and long-term outcomes after neonatal intensive care unit. Paediatr Anaesth 2014;24:60-7.

68. Bellù R, de Waal KA, Zanini R. Opioids for neonates receiving mechanical ventilation. Cochrane Database Syst Rev 2008;1:CD004212.

69. Batton DG, Barrington KJ, Wallman C. Prevention and management of pain in the neonate: an update. Pediatrics 2006;118:2231-41.

70. Pillai Riddell RR, Racine NM, Turcotte K, et al. Non-pharmacological management of infant and young child procedural pain. Cochrane Database Syst Rev 2011;5:CD006275.

71. Stevens B, Yamada J, Lee GY, Ohlsson A. Sucrose for analgesia in newborn infants undergoing painful procedures. Cochrane Database Syst Rev 2013;1:CD001069.

72. Taddio A, Yiu A, Smith RW, Katz J, McNair C, Shah V. Variability in clinical practice guidelines for sweetening agents in newborn infants undergoing painful procedures. Clin J Pain 2009;25:153-5.

73. Milgrom J, Newnham C, Anderson PJ, et al. Early sensitivity training for parents of preterm infants: impact on the developing brain. Pediatr Res 2010;67:330-5.

74. Brummelte S, Grunau RE, Zaidman-Zait A, Weinberg J, Nordstokke D, Cepeda IL. Cortisol levels in relation to maternal interaction and child internalizing behavior in preterm and full-term children at 18 months corrected age. Dev Psychobiol 2011;53:184-95. 